\title{
Front Matter: Volume 9293
}

, "Front Matter: Volume 9293," Proc. SPIE 9293, International Optical Design Conference 2014, 929301 (29 December 2014); doi: 10.1117/12.2181994

Event: International Optical Design Conference, 2014, Kohala Coast, Hawaii, SPIE. United States 


\title{
PROCEEDINGS OF SPIE
}

\section{International Optical Design Conference 2014}

\author{
Mariana Figueiro \\ Scott Lerner \\ Julius Muschaweck \\ John Rogers \\ Editors
}

\section{3-26 June 2014}

Kohala Coast, Hawaii, United States

Organized by

The Optical Society

Technical Cosponsor

SPIE

Sponsored by

American Elements Corporation

Edmund Optics, Inc.

Optimax Systems, Inc.

Rochester Precision Optics, LLC

Synopsys, Inc.

Published by

SPIE 
The papers included in this volume were part of the technical conference cited on the cover and title page. Papers were selected and subject to review by the editors and conference program committee. Some conference presentations may not be available for publication. The papers published in these proceedings reflect the work and thoughts of the authors and are published herein as submitted. The publisher is not responsible for the validity of the information or for any outcomes resulting from reliance thereon.

Please use the following format to cite material from this book:

Author(s), "Title of Paper," in International Optical Design Conference 2014, edited by Mariana Figueiro, Scott Lerner, Julius Muschaweck, John Rogers, Proceedings of SPIE-OSA Vol. 9293 (SPIE, Bellingham, WA, 2014) Article CID Number.

ISSN: 0277-786X

ISBN: 9781628413786

\section{Copublished by}

\section{The Optical Society (OSA)}

2010 Massachusetts Ave., N.W., D.C., 20036 USA

Telephone 1 202/223-8130 (Eastern Time) • Fax 1 202/223-1096

http:/www.osa.org

and

\section{SPIE}

P.O. Box 10, Bellingham, Washington 98227-0010 USA

Telephone +1 3606763290 (Pacific Time) · Fax +1 3606471445

SPIE.org

Copyright (c) 2014, The Optical Society (OSA) and Society of Photo-Optical Instrumentation Engineers

Copying of material in this book for internal or personal use, or for the internal or personal use of specific clients, beyond the fair use provisions granted by the U.S. Copyright Law is authorized by SPIE subject to payment of copying fees. The Transactional Reporting Service base fee for this volume is $\$ 18.00$ per article (or portion thereof), which should be paid directly to the Copyright Clearance Center (CCC), 222 Rosewood Drive, Danvers, MA 01923. Payment may also be made electronically through CCC Online at copyright.com. Other copying for republication, resale, advertising or promotion, or any form of systematic or multiple reproduction of any material in this book is prohibited except with permission in writing from the publisher. The CCC fee code is 0277-786X/14/\$18.00.

Printed in the United States of America.

Publication of record for individual papers is online in the SPIE Digital Library.

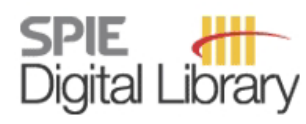

SPIEDigitalLibrary.org

Paper Numbering: Proceedings of SPIE follow an e-First publication model, with papers published first online and then in print and on CD-ROM. Papers are published as they are submitted and meet publication criteria. A unique, consistent, permanent citation identifier (CID) number is assigned to each article at the time of the first publication. Utilization of CIDs allows articles to be fully citable as soon as they are published online, and connects the same identifier to all online, print, and electronic versions of the publication. SPIE uses a six-digit CID article numbering system in which:

- The first four digits correspond to the SPIE volume number.

- The last two digits indicate publication order within the volume using a Base 36 numbering system employing both numerals and letters. These two-number sets start with 00, 01, 02, 03, 04, $05,06,07,08,09,0 A, 0 B \ldots$. OZ, followed by 10-1Z, 20-2Z, etc.

The CID Number appears on each page of the manuscript. The complete citation is used on the first page, and an abbreviated version on subsequent pages. Numbers in the index correspond to the last two digits of the six-digit CID Number. 


\title{
Contents
}

\author{
ix Authors \\ xi Conference Committees \\ $\mathrm{xv}$ Introduction
}

JOINT PLENARY SESSION

929302 Will computational imaging change lens design? (Invited Paper) [9293-91]

DESIGN CONTEST

929303 The 2014 IODC lens design problem: the Cinderella lens [9293-82]

929304 IODC 2014 Illumination Design Problem: the Cinderella lamp [9293-109]

\section{ASTRONOMY}

929305 Optical design of the WFIRST-AFTA wide-field instrument [9293-116]

929306 Ray-tracing for coordinate knowledge in the JWST Integrated Science Instrument Module [9293-87]

929307 CFRP variable curvature mirror used for realizing non-moving-element optical zoom imaging [9293-2]

929308 Characterization of DKIST retarder components with polarization ray tracing [9293-8]

929309 A fast, wide field of view, catadioptric telescope for Whipple [9293-117]

\section{EXOTIC OPTICS}

9293 0A Optical design considerations for wide spectral band applications using refractive optics [9293-11]

9293 OB Flexible and robust beam shaping concepts with aspherical surfaces [9293-20]

9293 OC Multi-emitter laser multiplexer using a two-mirror beam shaper [9293-21] 
9293 OD Analysis of the influence of manufacturing and alignment related errors on an optical tweezer system [9293-30]

9293 OE Research of beam conditioning technologies on SG-III laser facility [9293-43]

9293 OF Generalized aberration reduction procedure of a concave grating for hyperspectral imaging [9293-48]

9293 OG Towards an optimized Gabor Superlens [9293-61]

$9293 \mathrm{OH}$ A multi-aperture imager for a wearable camera [9293-66]

9293 Ol Modeling and measuring liquid crystal tunable lenses [9293-68]

\section{FREEFORM OPTICS}

9293 0J Design of light field head-mounted display [9293-99]

9293 OK Tackling freeform aberrations by ray-mapping analysis [9293-108]

9293 OL Pamplemousse: the optical design, fabrication, and assembly of a three-mirror freeform imaging telescope (Invited Paper) [9293-90]

9293 OM Initial design with $\mathrm{L}^{2}$ Monge-Kantorovich theory for the Monge-Ampère equation method of freeform optics [9293-14]

9293 ON New freeform NURBS imaging design code [9293-34]

929300 Spectral full-field displays for spectrometers [9293-50]

9293 OP Optical design of off-axis astronomical space telescope based on freeform surfaces [9293-55]

$92930 Q \quad T w o$ all reflective, freeform, optical see-through head-worn displays [9293-60]

9293 OR Simultaneous control on the intensity and phase profile of laser beam with Monge-Ampère equation method [9293-69]

9293 OS Free form surfaces in imaging optics [9293-78]

9293 OT Description and tolerancing of freeform surfaces in standards [9293-110]

9293 OU Solving the wall wash problem with a single lens [9293-112]

9293 OV Uniform and efficient illumination with saddle lenses [9293-113] 
9293 OW All-plastic high-performance eyepiece design utilizing a spherical gradient-index lens [9293-84]

$92930 \mathrm{X}$ Optical design study in the 1-5 $\mu \mathrm{m}$ spectral band with gradient-index materials [9293-26]

9293 OY Axial and lateral color correction in zoom lenses utilizing gradient-index copolymer elements [9293-63]

$92930 Z$ Bi-AGRIN Sphero-Apochromats [9293-106]

\section{LED OPTICS/SOLAR}

929310 Optical design for a LED search light [9293-15]

$929311 \quad$ Hollow backlight parametric study [9293-5]

929312 XRX-Köhler optical design and illumination optimization [9293-38]

929313 Challenges for reducing the size of laser activated remote phosphor light engines for DLP projection [9293-52]

929314 Engineered optical films with microstructures for solid state lighting applications [9293-62]

929315 Tracking-integrated optics: applications in solar concentration [9293-93]

929316 Freeform lens design to achieve 1000X solar concentration with a parabolic trough reflector [9293-114]

\section{MEASUREMENT/MANUFACTURING}

929317 Standards: a key element of optical design, engineering productivity, and time to market [9293-101]

929318 Efficient assessment of lens manufacturability in optical design [9293-16]

929319 Measurement and simulation of isotropic and anisotropic diffusers [9293-65]

9293 1A Passive athermalization: required accuracy of the thermo-optical coefficients [9293-95]

\section{MEDICAL/BIOLOGY}

9293 1B A design approach for an innovative LED surgical light [9293-9]

9293 1C Retinal imaging with virtual reality stimulus for studying Salticidae retinas [9293-51] 
9293 1D 193-nm scatterfield microscope illumination optics [9293-81]

9293 IE Broadband high-resolution gradient-index micro-objectives for optical biopsy systems [9293-27]

$9293 \mathrm{lF} \quad$ Optical design of an optical coherence tomography and multispectral fluorescence imaging endoscope to detect early stage ovarian cancer [9293-76]

9293 IG Illumination in microlithography [9293-97]

\section{OPTIMIZATION}

$92931 \mathrm{H} \quad$ Rapid lens design and prototype with stock lenses [9293-105]

$929311 \quad$ Automatic design of multi-lens optical systems based on stock lenses for high power lasers [9293-92]

$92931 \mathrm{~J} \quad$ Use of very low departure aspheric surfaces in high quality camera lenses [9293-10]

$92931 \mathrm{~K}$ Algorithms and examples for chromatic aberration correction and athermalization of complex imaging systems [9293-23]

$92931 \mathrm{~L} \quad$ Noise as a design constraint in broadband wavefront coded optical systems [9293-67]

\section{PHOTOGRAPHY}

$92931 \mathrm{M}$ Mobile plafform optical design (Invited Paper) [9293-115]

$92931 \mathrm{~N}$ Design, fabrication and test of miniature plastic panomorph lenses with $180^{\circ}$ field of view [9293-86]

929310 Folded zoom lenses: a review of patent literature [9293-7]

9293 IP Fast calculation of bokeh image structure in camera lenses with multiple aspheric surfaces [9293-33]

$92931 Q \quad$ Digital imaging system design and trade space analysis [9293-94]

\section{THEORY}

9293 IR Color correction strategies in optical design (Invited Paper) [9293-100]

9293 is Generally astigmatic Gaussian beam representation and optimization using skew rays [9293-6] 
9293 IT Development of an image restoration technique using the OTF of imaging systems [9293-29]

$92931 \mathrm{U}$ Fat rays revisited: a synthesis of physical and geometrical optics with Gaußlets [9293-36]

9293 IV Nodal aberration theory applied to freeform surfaces [9293-44]

9293 IW Extended depth of field in an intrinsically wavefront-encoded biometric iris camera [9293-64]

$92931 \mathrm{X}$ A review of skew aberration, the intrinsic polarization aberration in high NA optical systems [9293-71]

9293 IY A lens-resolved approach for analyzing and correcting secondary color [9293-74]

929312 Grey's orthonormal optimization: a 50-year retrospective [9293-75]

929320 Observations on the formulation of paraxial and Gaussian optics [9293-96]

9293212013 China lens design problem: the conjugate zoom lens [9293-104]

929322 Field curvature aberration [9293-111]

TOLERANCING

929323 Passive thermal stabilization [9293-83]

929324 Statistical case for specifying tolerances of doublet lenses jointly [9293-45]

929325 Aberration-insensitive lens shuffle [9293-54]

929326 Scanning pupil tolerancing [9293-58]

$929327 \quad$ An efficient method of reducing glass dispersion tolerance sensitivity [9293-77]

929328 Integrating optical fabrication and metrology into the optical design process (Invited Paper) [9293-102] 
SPIE-OSA/ Vol. $9293929301-8$

Downloaded From: https://www.spiedigitallibrary.org/conference-proceedings-of-spie on 26 Apr 2023 Terms of Use: https://www.spiedigitallibrary.org/terms-of-use 


\section{Authors}

Numbers in the index correspond to the last two digits of the six-digit citation identifier (CID) article numbering system used in Proceedings of SPIE. The first four digits reflect the volume number. Base 36 numbering is employed for the last two digits and indicates the order of articles within the volume. Numbers start with 00, 01, 02, 03, 04, 05, 06, 07, 08, 09, OA, OB...0Z, followed by 10-1Z, 20-2Z, etc.

Adelsberger, Kathleen, $1 \mathrm{~L}$ Aikens, David M., OT, OU, 17 Angel, Roger, 12, 15, 16

Armani, Nerses, 05

Barton, Jennifer, $1 \mathrm{~F}$

Bates, Rob, 1Q

Baver, Aaron, $0 Q$

Benítez, Pablo, OM

Bentley, Julie L., 1E, IW

Bergkoetter, Matthew D., IW

Berman, Rebecca, OX

Bhatia, Vikram, OC

Black, John, IF

Boye, Robert, $1 \mathrm{~L}$

Brennan, John, OC

Bruemmer, Mathias, 13

Canavesi, Cristina, 1C

Cassarly, William J., 04

Cheng, Dewen, 0J, 1H, 21

Chipman, Russell A., 08, 1X

Chrisp, Michael P., ON

Clark, Peter P., Ol, $1 \mathrm{M}$

Cobb, Joshua M., OC

Colbourne, Paul D., is

Content, David, 05

Corsetti, James A., OY

Coughenour, Blake, 12, 15, 16

Dalzell, Kristen E., 1 J

Davis, Gregg E., OL

Dong, Jun, OE

Du, Yunfei, 07

Elmore, David F., 08

Epple, Alexander, OS

Fan, Xuewu, 07

Fang, Kejia, OW

Fuchs, Ulrike, OB

Fuerschbach, Kyle, 0L, IV

Gong, Qian, 05

Greengard, Adam, 1Q

Greivenkamp, John E., 20

Greynolds, Alan W., $1 \mathrm{U}$

Hadrath, Stefan, 1B

Hartwig, Ulrich, 13

Harvey, James E., 28

Hatakeyama, Koshi, $1 T$

Hayford, Michael J., 1 Z

Hengesbach, Stefan, 11

Herkommer, Alois M., OK

Herman, Eric, 18
Hoffmann, Dieter, 11

Howard, Joseph, 05

$\mathrm{Hu}$, Dongxia, OE

Jakob, Elizabeth, 1C

Jenkins, David R., 11

Jonas, Reginald P., 1 J

Juergens, Richard C., 03

Jurling, Alden, 05

Kampmann, R., OD

Keenan, Molly, IF

Kehoe, Michael, 24

Kiontke, Sven R., OT, 17

Ko, Cheng-Hao, OF

Kruk, Jeffery, 05

Kuan, Gary, 05

Kubala, Kenneth, 1Q

Kubalak, David, 06

Lahner, Mark, OU

Lam, Wai Sze T., $1 \mathrm{X}$

Langenbach, Eckhard, 23

Li, Haifeng, OR

Li, Ping, OE

Lipp, Markus, 23

Liu, $X \cup, O R$

Liu, Yue, OJ

Long, Skye, 1C

Loosen, Peter, 11

Ma, Zhen, 07

Magarill, Simon, 11

Manhart, Paul K., $\mathrm{OZ}$

McCarthy, Peter, OX

McGuire Jr., James P., 09

McLaughlin, Paul O., 19

Mentzell, Eric, 05

Miñano, Juan C., OM

Miyawaki, Mamoru, $\mathrm{OH}$

Moore, Duncan T., OW, OX, OY

Morgenbrod, Nico, 1B

Moritz, Jens, OB

Nobis, Thomas, $1 Y$

Pang, Zhihai, 07

Parent, Jocelyn, $1 \mathrm{~N}$

Pasquale, Bert, 05

Pendleton, Amanda, 19

Peng, Zhitao, OE

Peyghambarian, Nasser, $\mathrm{OH}$

Pfisterer, Richard N., IR

Qu, He-meng, OP

Radl, Bruce, 14 
Rehn, H., 10

Reiley, Daniel J., 10

Reimers, Jacob, 00

Ren, Guorui, 07

Reshidko, Dmitry, $\mathrm{OH}, 1 \mathrm{~K}$

Rogers, John R., $1 \mathrm{~A}$

Rohrbach, Scott, 06

Rolland, Jannick P., 02, OL, 0O, 0Q, 1C, IV

Roulet, Patrice, $1 \mathrm{~N}$

Sabatke, Derek, 06

Sales, Tasso R. M., OV

Sanson, Mark C., 26

Sasián, José, $\mathrm{OH}, 18,1 \mathrm{~K}, 22$

Saupe, Frank, 23

Schertler, Donald J., 19

Schiesser, Eric, 1C

Schmidt, Greg R., OW, OY

Seals, Len, 05

Shepard, R. Hamilton, 0G, 27

Sheppard, Giles, 25

Shi, Guang-wei, OP

Sivokon, V.P., IP

Silver, Richard M., 1D

Sinzinger, S., OD

Smith, Daniel G., $1 G$

Sohn, Martin Y., ID

Song, Weitao, OJ

Sparrold, Scott W., 27

Spencer, Harvey M., OA

Su, Jingqin, $O E$

Su, Yu, 07

Sueoka, Stacey R., 08

Sullivan, Joseph, 06

Swan, Elizabeth, $1 \mathrm{~F}$

Tang, Chia-Hui, OF

Tate, Tyler, IF

Thibault, Simon, $1 \mathrm{~N}$

Thompson, Kevin P., 02, 0L, 00, $1 \mathrm{~V}$

Thorpe, Michael D., 1J, $1 \mathrm{P}$

Tian, Xiaocheng, OE

Traub, Martin, II

Tsai, Jih-Run, OF

Utzinger, Urs, $1 \mathrm{~F}$

Vaughnn, David, 05

Visconti, Anthony J., OW, IE

Vorndran, Shelby D., IR

Wang, Bang-Ji, OF

Wang, Chao, OP

Wang, Fang, OE

Wang, Jianjun, OE

Wang, Ling-jie, OP

Wang, Qiwei, $1 \mathrm{H}$

Wang, Wei, 07

Wang, Yongtian, $0 \mathrm{~J}, 1 \mathrm{H}, 21$

Wang, Yuancheng, OE

Wang, Zhuo, 14

Watanabe, Takeshi, $1 \mathrm{~T}$

Wei, Jingxuan, 07

Wheelwright, Brian M., 15, 16

Whiteaker, Kevin L., 00
Williams, Daniel J. L., OX

Wu, Hong-bo, OP

Wu, Rengmao, OM, OR

Wu, Yan-xiong, OP

Xie, Yongjie, 07

$\mathrm{Xu}$, Chen, $1 \mathrm{H}$

Yang, Haiyue, OK

Yee, Anthony, OX

Young, Garam, IX

Youngworth, Richard N., OT, 17, 18

Yuan, Haoyu, OE

Yuan, Qiang, OE

Zavislan, James, $1 \mathrm{~L}$

Zeng, Fei, OP

Zhang, $\mathrm{Hu}, \mathrm{IN}$

Zhang, Jian-ping, OP

Zhang, Ji-zhen, OP

Zhang, Rui, OE

Zhang, Xiaomin, OE

Zhang, Xin, OP

Zhang, Yaqin, OM, OR

Zhang, Ying, OE

Zhao, Hui, 07

Zheng, Wanguo, OE

Zheng, Zhenrong, OR

Zhou, Wei, OE

Zhu, Qihua, OE

Zhu, Yang, OP 


\title{
Conference Committees
}

\author{
Conference Chairs
}

Mariana Figueiro, Rensselaer Polytechnic Institute (United States)

Scott Lerner, Carl Zeiss AG (United States)

Julius Muschaweck, ARRI (Germany)

John Rogers, Synopsys, Inc. (United States)

Program Committee

Dave Aikens, Savvy Optics Corporation (United States)

Miguel Alonso, University of Rochester (United States)

Rob Bates, FiveFocal LLC (United States)

Julie Bentley, University of Rochester (United States)

Florian Bociort, Technische Universiteit Delft (Netherlands)

Peter Brick, OSRAM Opto Semiconductors GmbH (Germany)

Thomas Brown, University of Rochester (United States)

Scott Cahall, Eastman Kodak Company (United States)

William Cassarly, Synopsys, Inc. (United States)

Chir-Weei Chang, Industrial Technology Research Institute (Taiwan)

Russell Chipman, The University of Arizona (United States)

Peter Clark, LensVector, Inc. (United States)

Josh Cobb, Corning Tropel Corporation (United States)

Jim Contreras, Ball Aerospace \& Technologies Corporation

(United States)

Jasmin Cote, Side by Side Optical Engineering (Canada)

Marta De La Fuente, INDRA (Spain)

J. Rufino Diaz-Uribe, Universidad Nacional Autónoma de Mexico

(Mexico)

Alexander Epple, Carl Zeiss AG (Germany)

Florian Fournier, Apple, Inc. (United States)

Edward Freniere, Lambda Research Corporation (United States)

G. Groot Gregory, Synopsys, Inc. (United States)

John Greivenkamp, The University of Arizona (United States)

Anurag Gupta, Google, Inc. (United States)

Lakshminarayan Hazra, University of Calcutta (India)

Joseph Howard, NASA Goddard Space Flight Center (United States)

Richard Juergens, Raytheon Missile Systems Company (United States)

Norbert Kerwien, Carl Zeiss AG (Germany)

David Kessler, Kessler Optics \& Photonics Solutions Ltd. (United States)

John Koshel, The University of Arizona (United States)

Kenneth Kubala, FiveFocal LLC (United States)

Jay Kumler, JENOPTIK Optical Systems LLC (United States)

Wai-sze Tiffany Lam, University of Arizona (United States) 
Paul Leisher, nLight Corporation (United States)

Rongguang Liang, University of Arizona (United States)

Irina Livshits, NRU ITMO (Russian Federation)

Virendra Mahajan, The Aerospace Corporation (United States)

Daniel Malacara Hernandez, Centro de Investigaciones en Optica

AC (Mexico)

Stephan Malkmus, OSRAM GmbH (Germany)

Paul Manhart, Sigma Space Corporation (United States)

Romeo Mercado, RM Optical Design Consulting (United States)

Paul Michaloski, Corning Advanced Optics (United States)

Michael Missig, Bausch \& Lomb, Inc. (United States)

Kenneth Moore, Radiant Zemax, LLC (United States)

Pantazis Mouroulis, Jet Propulsion Laboratory (United States)

Iain Neil, Scotoptix (Switzerland)

Thomas Nobis, Carl Zeiss AG (Germany)

Vladimir Oliker, Emory University (United States)

Craig Olson, L-3 Communications (United States)

Donald O'Shea, Georgia Institute of Technology (United States)

Richard Pfisterer, Photon Engineering LLC (United States)

Andrew Rakich, European Southern Observatory (Germany)

Henning Rehn, OSRAM GmbH (Germany)

Jannick Rolland, University of Rochester (United States)

Kevin Rolland-Thompson, Synopsys, Inc. (United States)

Martha Rosete-Aguilar, Universidad Nacional Autónoma de Mexico (Mexico)

Jose Sasian, The University of Arizona (United States)

David Shafer, David Shafer Optical Design (United States)

Vesselin Shaoulov, University of Central Florida (United States)

Narkis Shatz, Science Applications International Corporation

(United States)

Bryan Stone, Synopsys, Inc. (United States)

Wilhelm Ulrich, Carl Zeiss AG (Germany)

Sergio Vazquez-Montiel, Universidad Politécnica de Tulancingo (Mexico)

Yongtian Wang, Beijing Institute of Technology (China)

Rolf Wartmann, Carl Zeiss Microimaging GmbH (Germany)

David Williamson, Nikon Research Corporation of America (United States)

Andrew Wood, Qioptiq Ltd. (United Kingdom)

Akira Yabe, Akira Yabe Lens Design (Germany)

Garam Young, Synopsys, Inc (United States)

Richard Youngworth, Riyo LLC (United States)

Maria Yzuel, Universidad Autònoma de Barcelona (Spain) 
Lens Design Problem Committee

Richard Juergens, Raytheon Missile Systems Company (United States)

Paul Manhart, Sigma Space Corporation (United States)

Andrew Wood, Qioptiq Ltd. (United Kingdom)

Thomas Nobis, Carl Zeiss AG (Germany)

David Shafer, David Shafer Optical Design (United States)

Illumination Design Problem Committee

William Cassarly, Synopsys, Inc. (United States)

Josh Cobb, Corning Tropel Corporation (United States)

John Koshel, The University of Arizona (United States)

Paul Michaloski, Corning Advanced Optics (United States)

Session Chairs

Joint Plenary Session

Jannick Rolland, University of Rochester (United States)

1 Photography

Kenneth Kubala, FiveFocal LLC (United States)

2 Exotic Optics 1

Michael Missig, Bausch \& Lomb, Inc. (United States)

3 Astronomy

Joseph Howard, NASA Goddard Space Flight Center (United States)

4 Microscopy/Lithography

Alexander Epple, Carl Zeiss AG (Germany)

$5 \quad$ Measurement/Manufacturing

Henning Rehn, OSRAM GmbH (Germany)

6 Theory I

Andrew Rakich, European Southern Observatory (Germany)

$7 \quad$ Tolerancing

Dave Aikens, Savvy Optics Corporation (United States)

8 Exotic Optics II

David Williamson, Nikon Research Corporation of America

(United States)

9 Optimization

Garam Young, Synopsys, Inc. (United States) 
GRIN

Julie Bentley, University of Rochester (United States)

11 Theory II

Craig Olson, L-3 Communications (United States)

12 Medical/Biology

Thomas Brown, University of Rochester (United States)

13 LED Optics/Solar

John Koshel, The University of Arizona (United States)

14 Freeform Optics I

Richard Pfisterer, Photon Engineering LLC (United States)

15 Freeform Optics II

Kevin Rolland-Thompson, Synopsys, Inc. (United States)

16 Freeform Optics III

William Cassarly, Synopsys, Inc. (United States) 


\section{Introduction}

The International Optical Design Conference (IODC) series, has been held approximately every four years, on a regular basis since 1975, when it was held at Haverford College, in Pennsylvania. Formerly IODC was known as ILDC, with an emphasis on "Lens Design" rather than "Optical Design." The 2014 IODC took place at the beautiful Kohala Coast, just north of Kona, Hawaii.

Over the nearly four decades in which the conference has been held, the IODC has remained the premier forum for exchange of ideas among optical designers. The IODC captures the progress in the continuously evolving fields of imaging optical design, and more recently, illumination optical design. Optics, a discipline as old as science itself, permeates our world today.

As always, the IODC 2014 brought together an international group of experts in the field of optical design, and included many familiar faces, as well as newer practitioners in the field. In an intense four day program filled with outstanding plenary, invited and contributed talks, the attendees shared their insights in a wide variety of areas. The talks covered the whole range from new scientific results in practical topics like tolerancing, and from well-established fields like microscopy to novel, exotic applications.

In what has become a modern tradition, the IODC was co-located with other conferences on related topics: Optical Fabrication and Testing (OF\&T) and Computational Optical Sensing and Imaging (COSI). A special highlight was the "Freeform Day" with three full sessions on freeform optics, both from imaging and illumination viewpoints.

The program committee did an excellent job to promote the conference, solicit contributed papers, and to provide high quality reviews of the over 140 submitted papers.

The joint plenary session for all three conferences featured three speakers: Dr. Jeff R. Kuhn from the University of Hawaii introduced us to the Colossus Project, dedicated to finding Earth-like civilizations in the galactic neighborhood; Dr. David Brady from Duke University spoke about the challenge to measure everything - the complete spectral light field at an aperture; finally, Dr. Kevin Rolland-Thompson brought the fields of computational imaging and lens design together, showing us how advances in one field will significantly change the other.

The IODC program had 16 sessions on a wide variety of topics, including 16 invited talks, complemented by a joint poster session with OF\&T and COSI on Tuesday night. The overall quality of the presentations was widely regarded as outstanding, up to the high standard that IODC had been setting over the years. 
We were fortunate to have several award ceremonies at the conference. Dr. Juan Carlos Miñano received the prestigious Joseph Fraunhofer Award/Robert M. Burley Prize, for his discovery of exceptional new design methods both for imaging and illumination optics, during more than three decades. The Michael Kidger Memorial Scholarship Award went to Brian Wheelwright this year, a PhD student at the University of Arizona.

The award for "Best Student Paper" was presented to Tzu-Yu Wu of the University of Arizona, with co-authors Arthur Gmitro and Andrew Rouse. Aaron Baver from the University of Rochester, Stacey Suoka and Tamer Elazhary, both from the University of Arizona, all received the Robert S. Hilbert Memorial Student Travel Grants, helping them to fund their travel. Thanks to the sponsors of all these awards, and to the volunteers who served on the award committees. Their generous efforts show the dedication of the optical design community members to their field.

We have been honored to serve as chairs for IODC 2014. It is the joint effort of many people that makes IODC a unique event, time and again, capturing the state of our fascinating field every four years. Special thanks go to all companies and institutions that have the vision and the generosity to let their employees help to make conferences like IODC happen. We thank IODC's corporate sponsors, namely American Elements, Edmund Optics, Optimax, Rochester Precision Optics, and Synopsys, for their generous financial support. Thanks also go to all of our exhibitors and authors. We thank OSA and SPIE for supporting IODC, time and again. Thank you, Groot Gregory, for managing the IODC web site, www.iodc.info. Special appreciation is extended to OSA, and SPIE, who worked hard and gave their best to make IODC 2014 the positively memorable event that it was, and to create this proceedings volume.

Finally, we thank everyone for taking the time and effort to travel to Hawaii, to share your insights and your expertise, keeping the optical design community thriving and alive. We look forward to seeing you at future International Optical Design Conferences. For further information, please see the IODC website at www.iodc.info, which is regularly updated with new information about the next IODC.

\section{Mariana Figueiro Scott Lerner Julius Muschaweck John Rogers}

